\title{
Slit Molecules Prevent Entrance of Trunk Neural Crest Cells in Developing Gut
}

Article in International Journal of Developmental Neuroscience · December 2014

DOI: 10.1016/j.ijdevneu.2014.12.003 · Source: PubMed

CITATIONS

0

9 authors, including:

\section{Blanca R Ortega}

California State University, Northridge

3 PUBLICATIONS 354 CITATIONS

SEE PROFILE

Maria Elena de Bellard

California State University, Northridge

35 PUBLICATIONS 1,732 CITATIONS

SEE PROFILE
READS

101

\section{Dion Giovannone}

University of Southern California

3 PUBLICATIONS 20 CITATIONS

SEE PROFILE

Some of the authors of this publication are also working on these related projects:

Project role of Robo signaling in neural crest migration View project

Project $\quad$ Neural crest evolution View project 


\title{
Slit molecules prevent entrance of trunk neural crest cells in developing gut
}

\author{
Nora Zuhdi ${ }^{\mathrm{a}, 1}$, Blanca Ortega ${ }^{\mathrm{a}, 1}$, Dion Giovannone ${ }^{\mathrm{a}, 1}$, Hannah Ra $^{\mathrm{a}}$, Michelle Reyes ${ }^{\mathrm{a}}$, \\ Viviana Asención ${ }^{\mathrm{a}}$, Ian McNicoll ${ }^{\mathrm{a}}$, Le Ma ${ }^{\mathrm{b}}$, Maria Elena de Bellard ${ }^{\mathrm{a}, *}$ \\ a California State University Northridge, Biology Deptartment, MC 8303. 18111 Nordhoff Street. Northridge, CA 91330, USA \\ ${ }^{\mathrm{b}}$ Department of Neuroscience, Thomas Jefferson University, BLSB 306, Philadelphia, PA 19107, USA
}

\section{A R T I C L E I N F O}

\section{Article history:}

Received 3 December 2014

Accepted 4 December 2014

Available online 6 December 2014

\section{Keywords:}

Neural crest

Cell migration

Enteric nervous system

Robo

\begin{abstract}
A B S T R A C T
Neural crest cells emerge from the dorsal neural tube early in development and give rise to sensory and sympathetic ganglia, adrenal cells, teeth, melanocytes and especially enteric nervous system. Several inhibitory molecules have been shown to play important roles in neural crest migration, among them are the chemorepulsive Slit1-3. It was known that Slits chemorepellants are expressed at the entry to the gut, and thus could play a role in the differential ability of vagal but not trunk neural crest cells to invade the gut and form enteric ganglia. Especially since trunk neural crest cells express Robo receptor while vagal do not. Thus, although we know that Robo mediates migration along the dorsal pathway in neural crest cells, we do not know if it is responsible in preventing their entry into the gut. The goal of this study was to further corroborate a role for Slit molecules in keeping trunk neural crest cells away from the gut. We observed that when we silenced Robo receptor in trunk neural crest, the sympathoadrenal (somites 18-24) were capable of invading gut mesenchyme in larger proportion than more rostral counterparts. The more rostral trunk neural crest tended not to migrate beyond the ventral aorta, suggesting that there are other repulsive molecules keeping them away from the gut. Interestingly, we also found that when we silenced Robo in sacral neural crest they did not wait for the arrival of vagal crest but entered the gut and migrated rostrally, suggesting that Slit molecules are the ones responsible for keeping them waiting at the hindgut mesenchyme. These combined results confirm that Slit molecules are responsible for keeping the timeliness of colonization of the gut by neural crest cells.
\end{abstract}

() 2014 Elsevier Ltd. All rights reserved.

\section{Introduction}

The neural crest is a group of cells that emerge early in development from the dorsal neural tube and migrate along pathways that are characteristic of their axial level of origin (Bronner-Fraser et al., 1991; Le Douarin et al., 1992). Neural crest cells give rise to a good portion of the peripheral nervous system (PNS) formation, cranio-facial structures and even endocrine organs. Probably the most intrinsic and characteristic feature of these cells is their precise migratory pathways along their rostro-caudal axis (Gammill and Roffers-Agarwal, 2010; Theveneau and Mayor, 2012). One of its classic pathways is that of vagal neural crest cells. These vagal neural crest cells emerge from the caudal hindbrain (between somites 1 and 7) and migrate into the developing gut where they extensively

\footnotetext{
* Corresponding author. Tel.: +1 818677 6470; fax: +1 8186772034

E-mail address: maria.debellard@csun.edu (M.E. de Bellard).

1 These authors contributed equally.
}

divide and eventually differentiate into the enteric nervous system (ENS) cells (Burns et al., 2002; Kuo and Erickson, 2010, 2011). In contrast, trunk neural crest cells (those arising from 8 to 25 somite levels) never enter the gut (Erickson and Goins, 2000b; Le Douarin and Teillet, 1974b).

Many inhibitory molecules have been shown to play critical roles in determining neural crest migration patterns, especially, ephrinB family members (Krull et al., 1997) and Semaphorins (Eickholt et al., 1999; Gammill et al., 2006). However, none of these molecules were able to explain the differences between the ability of vagal and trunk neural crest populations to enter the gut. A clue came from finding that only migrating trunk neural crest cells expressed Slit Robo receptors (De Bellard et al., 2003). Slit proteins are not only well known chemorepellants for axons and neuronal migration (Brose et al., 1999; Kidd et al., 1999; Kinrade et al., 2001; Zhu et al., 1999) but in addition they are powerful repellents of trunk neural crest cells (De Bellard et al., 2003).

Seminal work from the labs of Le Douarin and Erickson showed that trunk crest cells transplanted to the vagal position could enter 


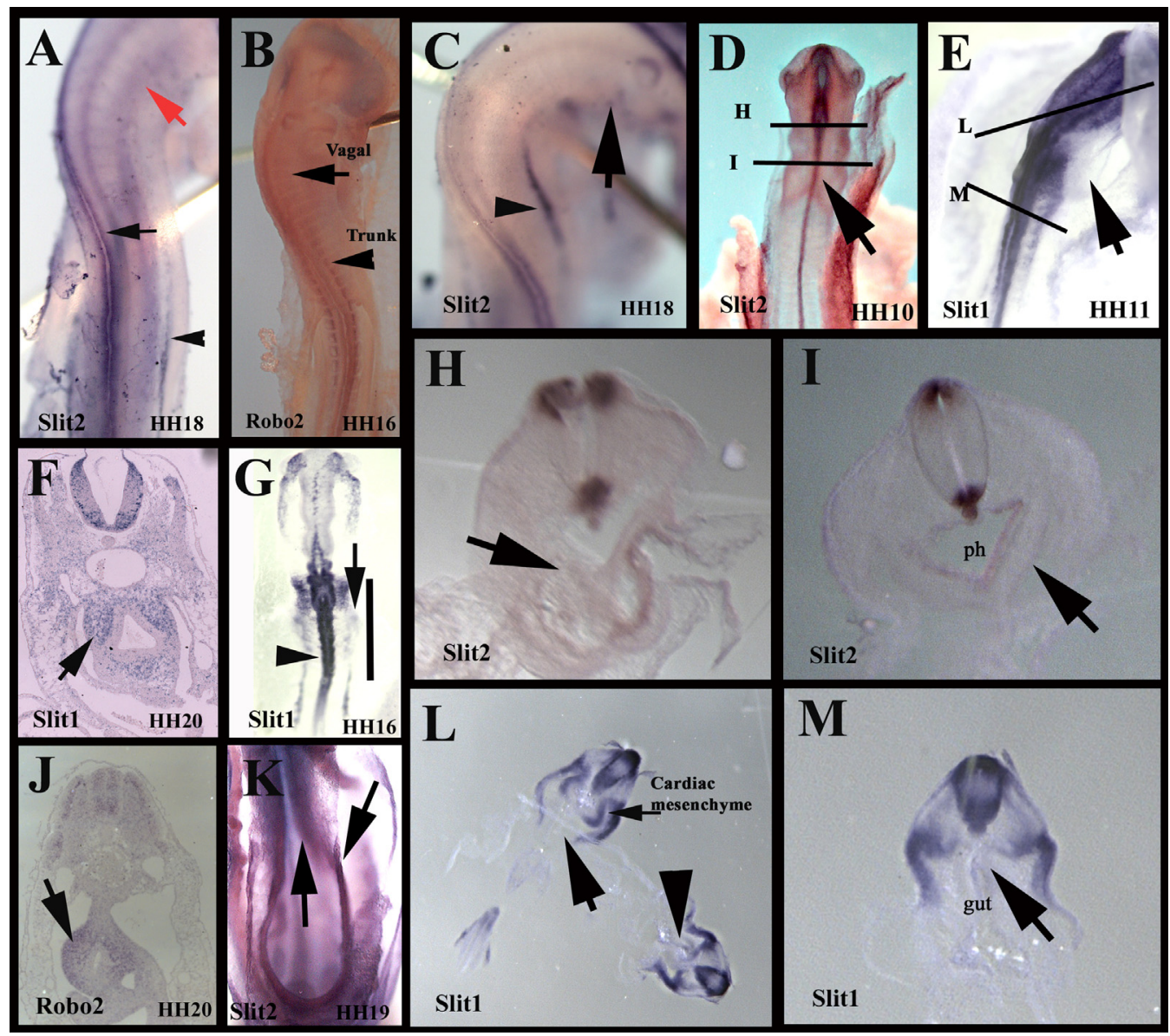

Fig. 1. Slit and Robo expression in chicken embryos.

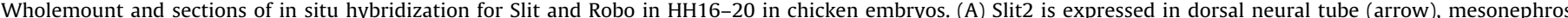

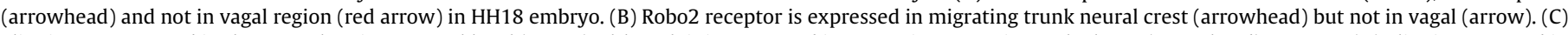

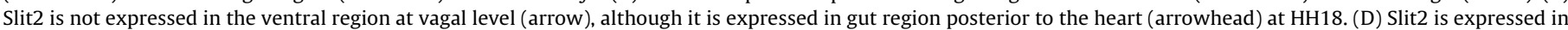

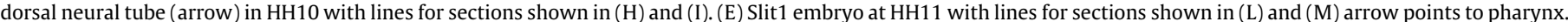

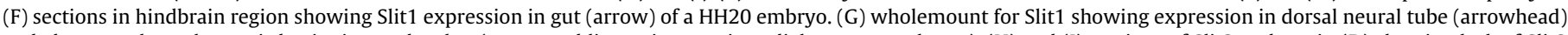

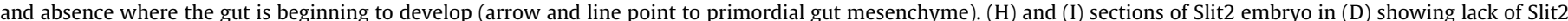

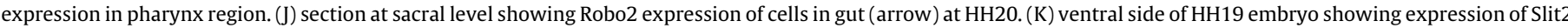

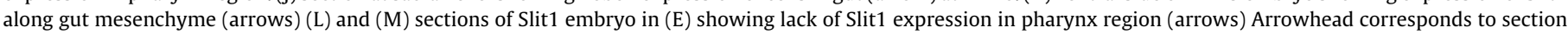
on (M) at higher magnification.

the gut, albeit never to the extent of vagal crest (Burns et al., 2002; Le Douarin and Teillet, 1974a ; Le Douarin and Teillet, 1973). These findings showed that trunk crest cells will not enter the developing gut, not that they are incapable of doing so. The key to their poor colonization came from studies by Newgreen and Burns labs which showed that the trunk cells failed to match vagal crest cells in proliferation once in the intestinal tissue, (Newgreen et al., 1980; Zhang et al., 2010) due to lack of ret receptor (Delalande et al., 2008). In addition, Burns and co-workers showed that the enteric neural crest shows cell autonomous differences in their migratory properties, with the vagal neural crest being more invasive of the gut than the caudal, sacral crest population. The reasons for this difference in invasive capacity between vagal and sacral crest has yet to be determined (Burns, 2005).

Here we further examined and settled the potential role of Slit molecules in keeping trunk neural crest cells from entering the gut. Slits are expressed near the entrance to the gut during trunk migration but not during vagal migration, while trunk and sacral neural crest express Robo receptors. We tested the hypothesis of a functional role for Slits in keeping trunk neural crest from migrating into and populating the gut by loss-of-function experiments via electroporation of a dominant negative Robo receptor. The results show for the first time that trunk and sacral neural crest cells can enter the gut if Robo receptors are silenced, thus giving account for the differential ability of vagal but not trunk neural crest cells to invade and innervate the gut. Interestingly, we also found axial differences in the invading capabilities into the gut between more rostral trunk versus sympathoadrenal trunk (somites 18-24), suggesting the presence of another repellant for trunk neural crest cells in the gut.

\section{Materials and methods}

\subsection{Animals}

Chicken embryos were obtained by incubating fertilized chicken eggs at $38^{\circ} \mathrm{C}$ as described by Hamburger and Hamilton (1951) until desired stage of development.

Mouse strains: all animals were generated in a mixed CD1/129Sv/C57Bl6 background. Robo mutants were obtained by crossing mice with Robo1 and Robo2 mutant alleles already linked (Ma and Tessier-Lavigne, 2007). Slit mutants were obtained by crossing Slit1 $1^{-/-}$; Slit2 ${ }^{+/-}$; Slit3 ${ }^{+/-}$animals (Plump et al., 2002; Yuan et al., 2003). PCR based genotyping was done following previously 
Table 1

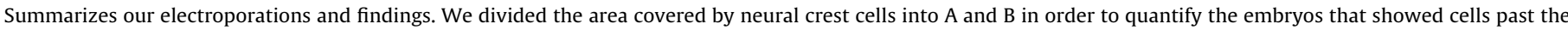

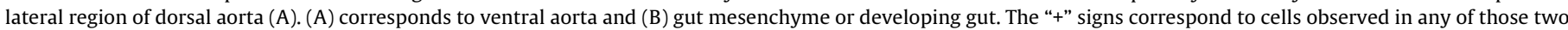

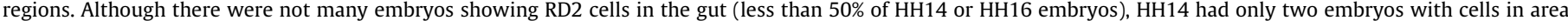
expressing Slit compared with HH16 sympathoadrenal or even more, HH17 sacral crest.

\begin{tabular}{|c|c|c|c|c|c|c|c|c|c|c|c|c|}
\hline \multirow[b]{2}{*}{ Embryo \# } & \multicolumn{2}{|c|}{$\begin{array}{l}\text { HH14 } \\
\text { GFP }\end{array}$} & \multicolumn{2}{|c|}{$\begin{array}{l}\mathrm{HH} 14 \\
\text { RD2 }\end{array}$} & \multicolumn{2}{|c|}{$\begin{array}{l}\text { HH16 } \\
\text { GFP }\end{array}$} & \multicolumn{2}{|c|}{$\begin{array}{l}\text { HH16 } \\
\text { RD2 }\end{array}$} & \multicolumn{2}{|c|}{$\begin{array}{l}\text { HH17 } \\
\text { GFP }\end{array}$} & \multicolumn{2}{|c|}{$\begin{array}{l}\mathrm{HH} 17 \\
\text { RD2 }\end{array}$} \\
\hline & A & B & A & B & A & B & A & B & A & B & A & B \\
\hline E1 & - & - & - & - & - & - & +++ & ++ & - & - & - & - \\
\hline E2 & - & - & - & - & - & - & +++ & + & - & - & - & - \\
\hline E3 & - & - & +++ & ++ & - & - & - & - & - & - & - & ++++ \\
\hline E4 & - & - & - & - & - & - & - & - & - & - & - & +++++ \\
\hline E5 & - & - & - & +++ & - & - & - & - & - & - & - & +++ \\
\hline E6 & - & - & - & - & - & - & ++++ & - & - & - & - & - \\
\hline E7 & - & - & $\mathrm{N} / \mathrm{A}$ & $\mathrm{N} / \mathrm{A}$ & - & - & - & - & $\mathrm{N} / \mathrm{A}$ & $\mathrm{N} / \mathrm{A}$ & $\mathrm{N} / \mathrm{A}$ & $\mathrm{N} / \mathrm{A}$ \\
\hline E8 & - & $\mathrm{N} / \mathrm{A}$ & $\mathrm{N} / \mathrm{A}$ & $\mathrm{N} / \mathrm{A}$ & - & - & $\mathrm{N} / \mathrm{A}$ & $\mathrm{N} / \mathrm{A}$ & $\mathrm{N} / \mathrm{A}$ & $\mathrm{N} / \mathrm{A}$ & $\mathrm{N} / \mathrm{A}$ & $\mathrm{N} / \mathrm{A}$ \\
\hline E9 & - & - & $\mathrm{N} / \mathrm{A}$ & $\mathrm{N} / \mathrm{A}$ & - & - & $\mathrm{N} / \mathrm{A}$ & $\mathrm{N} / \mathrm{A}$ & $\mathrm{N} / \mathrm{A}$ & $\mathrm{N} / \mathrm{A}$ & N/A & $\mathrm{N} / \mathrm{A}$ \\
\hline \multirow[t]{2}{*}{ E10 } & & $\mathrm{N} / \mathrm{A}$ & $\mathrm{N} / \mathrm{A}$ & $\mathrm{N} / \mathrm{A}$ & - & - & $\mathrm{N} / \mathrm{A}$ & $\mathrm{N} / \mathrm{A}$ & $\mathrm{N} / \mathrm{A}$ & $\mathrm{N} / \mathrm{A}$ & $\mathrm{N} / \mathrm{A}$ & $\mathrm{N} / \mathrm{A}$ \\
\hline & $0 / 9$ & $0 / 9$ & $1 / 6$ & $2 / 6$ & $0 / 10$ & $0 / 10$ & $3 / 7$ & $2 / 7$ & $0 / 6$ & $0 / 6$ & $0 / 6$ & $3 / 6$ \\
\hline
\end{tabular}

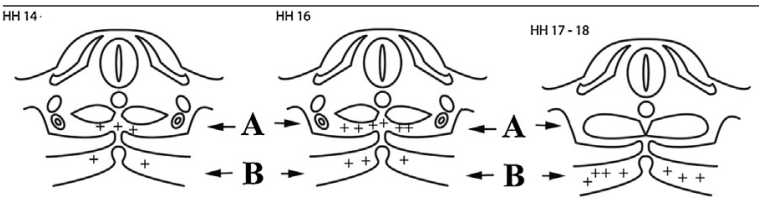

described protocols (Grieshammer et al., 2004; Plump et al., 2002; Sabatier et al., 2004; Yuan et al., 2003).

\subsection{In situ hybridization}

Chicken embryos were fixed in $4 \%$ paraformaldehyde (PFA) overnight before being stored in $0.1 \mathrm{M}$ phosphate buffered saline (PBS). Patterns of gene expression were determined by whole-mount in situ hybridization using DIG-labeled RNA antisense probes as described in Grove's lab website (http://www.bcmneuroscience.org/groveslab/protocols.php). The cSlit1, cSlit2, cRobo1 and mSox10 probes used are described in (De Bellard et al., 2003).

\subsection{Electroporations of chicken neural tubes}

Chicken embryos windowed and visualized with India ink $(10 \%$ in Ringer's solution) to determine their stage of development. After gently removing covering membrane, $1-2 \mathrm{mg} / \mathrm{ml}$ solution of DNA (pCAB-GFP, pCax-RoboD2) was injected into the embryos neural tubes using a mouth pipette and immediately electroporated with two $50 \mathrm{~ms}$ pulses of $20 \mathrm{mV}$ each. Embryos were sealed with tape and re-incubated for $24 \mathrm{~h}$. until fixation in $4 \%$ paraformaldehyde.

\subsection{Whole mount immunofluorescence}

After overnight incubation in blocking buffer (PBS with $1 \%$ Triton-X100,10\% goat serum), electroporated embryos were incubated with DAPI to visualize nuclei and photographed using Zeiss A-1 Axiolmager.

\section{Results}

\subsection{Distribution of Slit and Robo molecules in the developing chicken embryo}

Slit molecules became known as chemorepellants expressed along the pathways of growing axons (Kidd et al., 1999). But in addition to axonal pathfinding, Slit molecules are also expressed along neural crest migration pathways (De Bellard et al., 2003; Jia et al., 2005; Shiau et al., 2008). One which holds special relevance is its expression along the developing gut (De Bellard et al., 2003).
Here we revised this past data and looked at younger stages to do a more extensive analysis. We found that Slit molecules expression in the gut mesentery begins truly past vagal migration levels (Fig. 1). Slit2 and Robo2 in situ hybridization of HH16-19 chicken embryos, during the peak of trunk neural crest migration, shows that Slit2 is expressed along the primordial gut folds in the trunk (Fig. 1A, $\mathrm{C}$ and $\mathrm{K}$ ), while migrating trunk shows Robo2 expression in trunk, not vagal neural crest cells (Fig. 1B) (De Bellard et al., 2003). At later stages, $\mathrm{HH} 20$, we found that Slit 1 expression remained strong in the gut (Fig. 1F), and interestingly, we also found that Robo2 expression is quite strong in the gut, implying that it is up-regulated in enteric neural crest cells after they reach and cross Slit expressing gut mesentery tissues (Fig. 1J) (Long et al., 2004).

We also looked at Slits expression in HH10-11, during the peak of vagal neural crest migration. We found that Slit2 is expressed in the developing pharynx epithelia, but not in the surrounding mesenchyme through which vagal crest cells migrate (Fig. 1D, H and I). Similarly, Slit1 expression was not observed in pharynx mesenchyme, albeit it was in the cardiac mesoderm primordia (Fig. 1G, $\mathrm{L}$ and $\mathrm{M}$ ).

\subsection{Silencing Robo receptor in trunk neural crest cells allows them to enter and populate the developing gut}

If Slit/Robo interactions are crucial for the difference between vagal and trunk neural crest migratory capabilities into the gut, one would think that expressing Robo in vagal crest would prevent them from entering/populating the gut. However, when we did these electroporations in vagal or trunk neural crest there was practically no delamination from the neural tube (Giovannone et al., 2012).

There are several ways to knockout a signal: by mutating/knocking out its receptor, by RNAi/shRNA or by silencing the receptor by co-expression of a dominant negative form. This last one is powerful and simple in chicken embryos since we can control the timing, area of expression and follow specific cells apart from normal cells. Here, we performed a set of loss-of-function (LOF) experiments in chicken embryos using a dominant negative form of Robo 2 receptor in order to silence it in specifically in trunk neural crest cells (Hammond et al., 2005). Chicken embryos from HH14 to HH18 were electroporated along the trunk neural tube with control GFP or a dominant negative form of Robo2 (RD2, missing the cyto- 

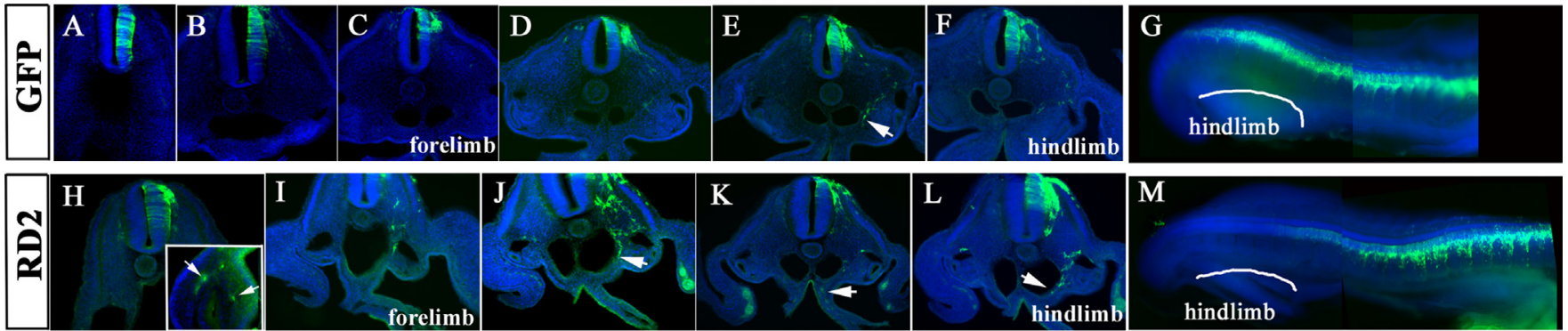

Fig. 2. Wholemount and rostro-to-caudal sections of HH14 embryos.

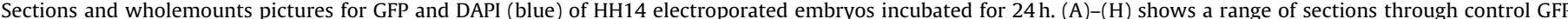

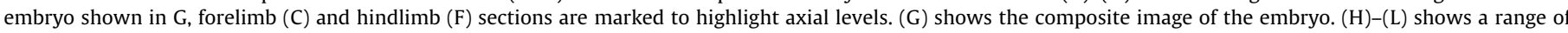

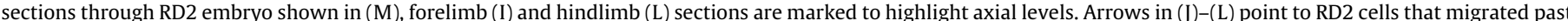

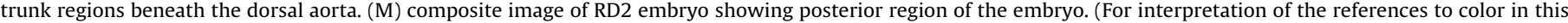
figure legend, the reader is referred to the web version of this article.)

plasmic domain). After $24 \mathrm{~h}$ of incubation we looked for presence or absence of migrated GFP cells in the developing gut in the Robo LOF embryos and compared with control GFP vector.

Table 1 summarizes our electroporations and findings. The first observation was that the younger the embryos the fewer the RD2 cells in the gut mesentery along the trunk region. Analogously to the work done by Erickson and Goins (2000b) we divided the area into $A$ and $B$ in order to quantify the embryos that showed cells past the lateral region of dorsal aorta. A corresponds to ventral aorta and B gut mesenchyme or developing gut. As could be observed, HH14 had only two embryos with cells in area B expressing Slit compared with HH16 sympathoadrenal or even more, HH17 sacral crest.

Embryos electroporated at HH14 (along somites 9-22), after vagal neural crest cells had migrated and before sacral crest appears, had few RD2 cells at the entrance of the gut past their sympathetic ganglia route (Fig. $2 \mathrm{H}-\mathrm{L}$ ). The RD2 cells found in these embryos corresponds to trunk neural crest from somites 9-17. The migrating cells were found along their normal ventro-medial routes with few that had gone beyond, migrating ventral to the dorsal aorta and in one instance we found two cells settled in the plexus area of the stomach (Fig. 2H insert). We only observed control GFP cells lateral to the dorsal aorta (Fig. 2).

We repeated this experiment, but this time we electroporated HH16 embryos from the tail end, thus we were also electroporating the sympathoadrenal crest (somites 18-24) and few to none of the first sacral crest cells. In these embryos, we found larger numbers of RD2 cells along the gut mesenchyme at hindlimb levels compared with previous experiments with younger embryos (Fig. 3). In these experiments we only observed RD2 cells in the hindgut region past the dorsal aorta, control embryos never showed GFP cells past the aorta. That is, sympathoadrenal crest cells were able to enter gut mesentery when we silenced Robo receptor.

Embryos electroporated from above the hindlimb towards the tail at late $\mathrm{HH} 17$ and $\mathrm{HH} 18$ showed a more dramatic response: they had significantly larger numbers of RD2 cells and these were seen migrating rostrally. Because the time and area from where these cells are delaminating (hindlimb region, somites 24-33), these cells correspond to crest of sympathoadrenal fate and the first sacral neural crest cells. Sections through these embryos further corroborated the presence of many cells in developing gut of RD2 embryos compared with control embryos. The larger number of $\mathrm{RD} 2$ cells was more noticeable in same regions analyzed in previous experiments, past forelimb and before the hindlimb. That is, larger numbers of sympathoadrenal cells and sacral crest cells as well (Fig. 4).

\subsection{Mice mutant for Slit or Robo show earlier development of enteric neurons}

Although analysis of knockout mice cannot differentiate between vagal or trunk neural crests cells, nevertheless it can still provide strong supporting evidence for our hypothesis. We looked at E12.5 Slit triple knockout and Robo1/2 knockout mutant mice, whole mounts of these mutant animals did not show striking differences in the trunk migration (data not shown). However, sections through Slit mutant embryos at the midtrunk level showed the

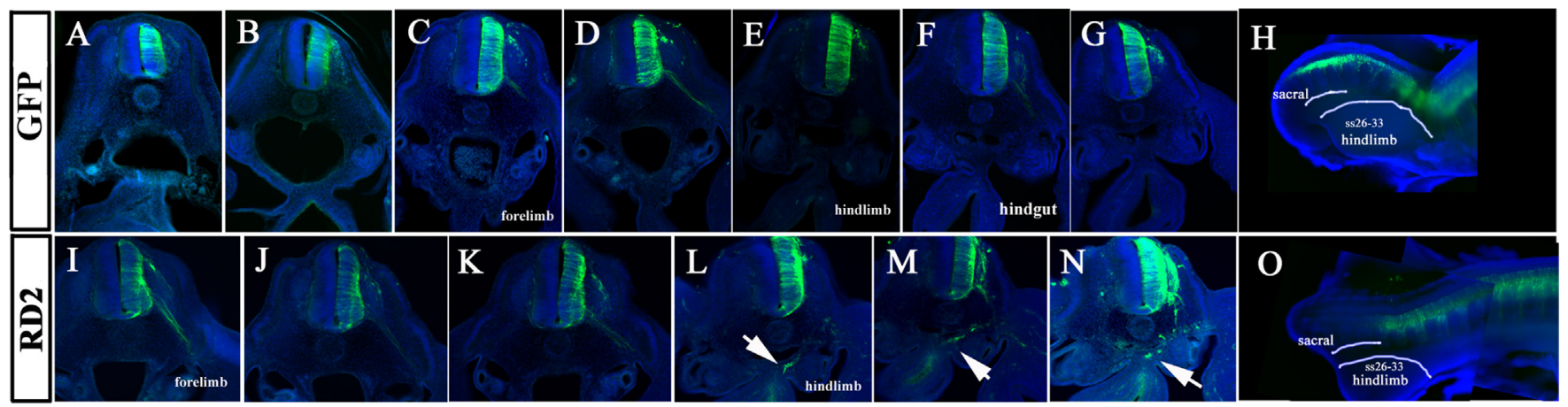

Fig. 3. Wholemount and rostro-to-caudal sections of HH16 embryos.

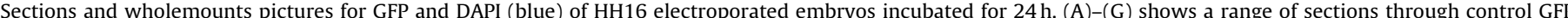

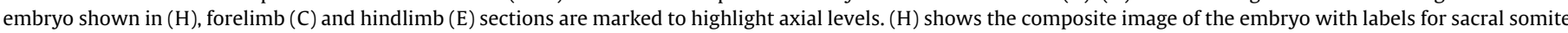

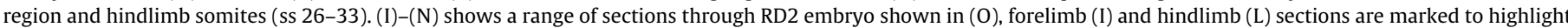

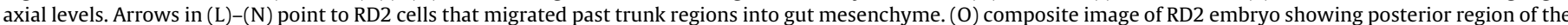

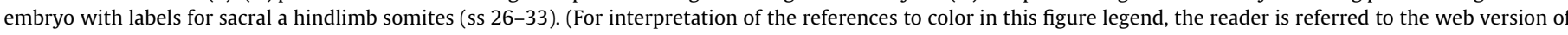
this article.) 

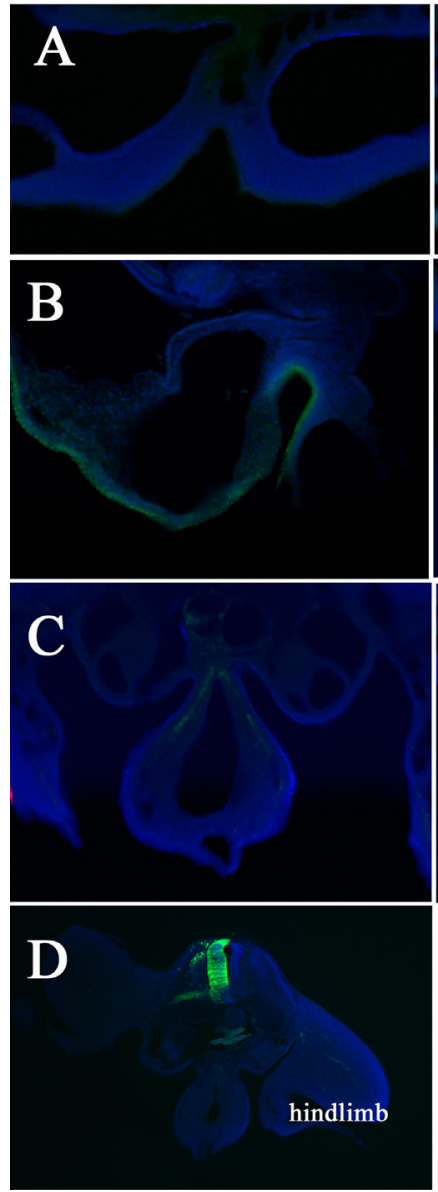
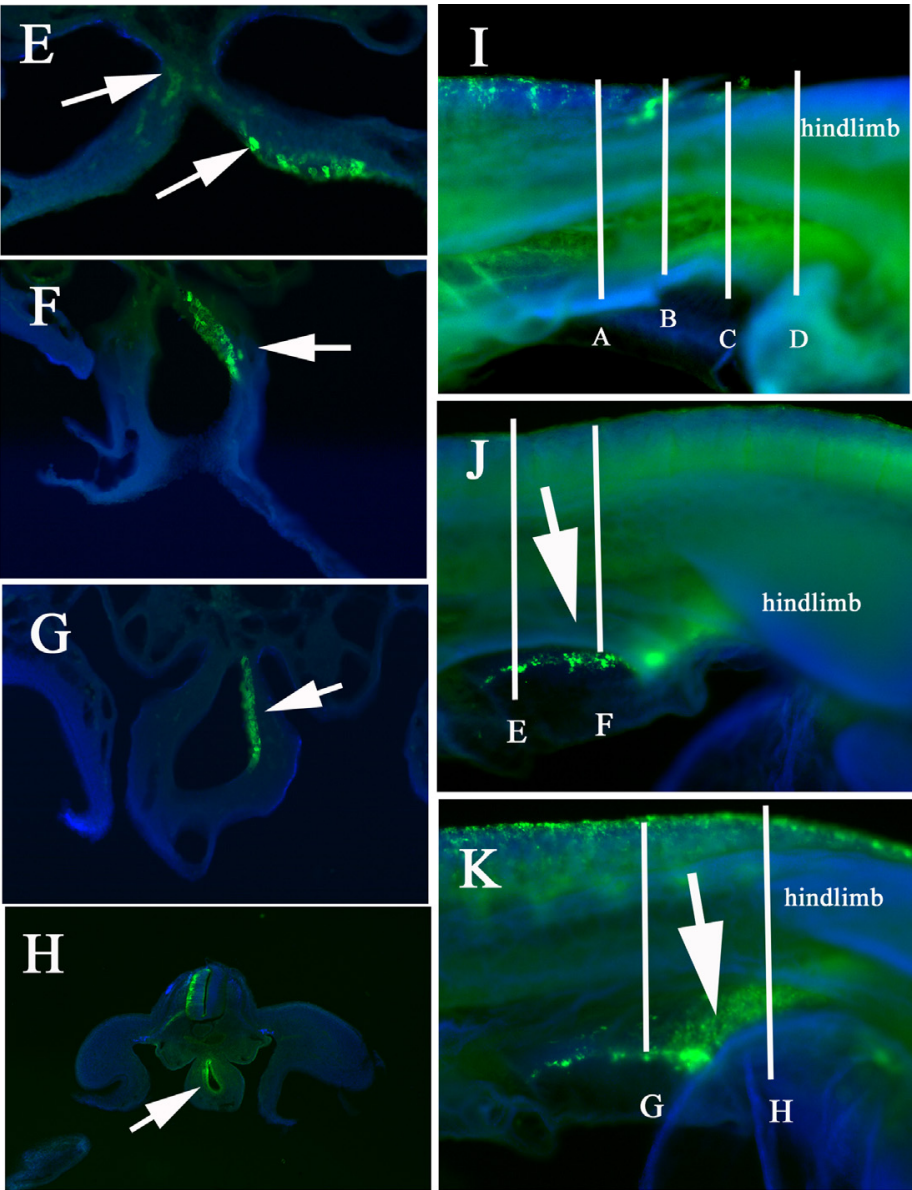

Fig. 4. Sacral neural crest cells enter gut in Robo LOF embryos.

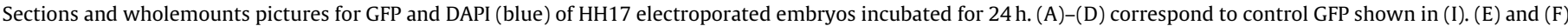

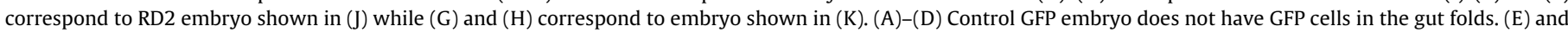

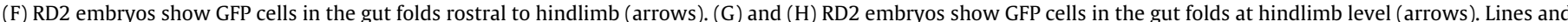

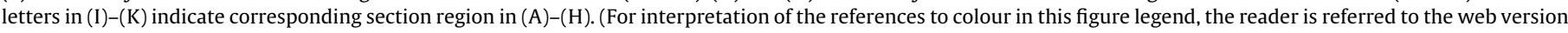
of this article.)

presence of Sox10 cells in the gut mesenchyme of mutant mice (either Slit1 ${ }^{-1-}$, Slit2 ${ }^{-1-}$, Slit3 ${ }^{-1-}$ or Slit $1^{-1-}$, Slit2 ${ }^{-1-}$, Slit3 ${ }^{+/+}$) compared with littermate embryos lacking only Slit1 (Slit1 ${ }^{-1-}$, Slit2 ${ }^{+/+}$, Slit3 ${ }^{+/+}$) (Fig. 5A-C). We also observed that in mutant mice, at the level of the lungs, the triple knockout mice have stronger Sox10 cells in the gut, already starting to look like enteric plexus, while counterparts missing only Slit1 had fewer Sox10 cells (Fig. 5D-G).

In order to determine if the colonization of the gut by trunk neural crest cells was Robo-dependent, we examined neural crest migration in double knockout mice for Robo1 and Robo2 with Tuj1 (which labels differentiated neurons). We observed the presence of larger number of Sox10 positive cells in the gut (data not shown) and differentiated enteric neurons determined by TuJ1 (Supplementary Fig. 1). We counted the Tuj1-positive cells in the developing mid-gut in mice and found that there were more in mutants compared with control wild type mice (wildtype $2.3+3.1$ versus knockout $12+4.8, p<0.001 T$-test). These observations from mutant Slit and Robo mice give great support for Slit/Robo role in neural crest cell migration during ENS development.

Supplementry material related to this article found, in the online version, at http://dx.doi.org/10.1016/j.ijdevneu.2014.12.003.

\section{Discussion}

It has been known that neural crest cells delaminating from trunk region (somites 8-27) will not enter or populate the developing gut of an embryo (Bronner-Fraser et al., 1991; Le Douarin et al., 1992; Le Douarin and Teillet, 1973). Although past research showed that Slits were true chemo-repulsive molecules for trunk neural crest cells, we were not certain that the reason why trunk crest cells would never continue migrating past the dorsal aorta and thus enter the developing mesentery was due to Slit molecules expression in that region (De Bellard et al., 2003). Here we show by carrying loss-of-function (LOF) experiments for Robo2 in chicken embryos that trunk sympathoadrenal neural crest cells can enter and populate the developing gut, thus demonstrating that Slit molecules are responsible for keeping trunk neural crest cells away from the gut.

The role of Slit/Robo signaling in keeping trunk crest away from developing gut has been investigated by comparing vagal versus trunk neural crest cells response to Slit molecules (De Bellard et al. 2003) and by carrying out gain-of-function experiments by overexpressing Slit or Robo in vagal and trunk neural crest (Giovannone et al., 2012). However, the findings from both studies did not settle the question whether Slit have a role in keeping trunk neural crest from migrating into the gut. Because neural crest cells practically did not delaminate when constitutively expressing Robo, we were not able to test if vagal crest expressing Robo would never enter the gut (Giovannone et al., 2012). Therefore, we needed to take a different approach to test this hypothesis. Here we addressed this caveat by silencing Slit/Robo signaling via Robo2 dominant negative receptor (RD2) and by looking at neural crest migration and 

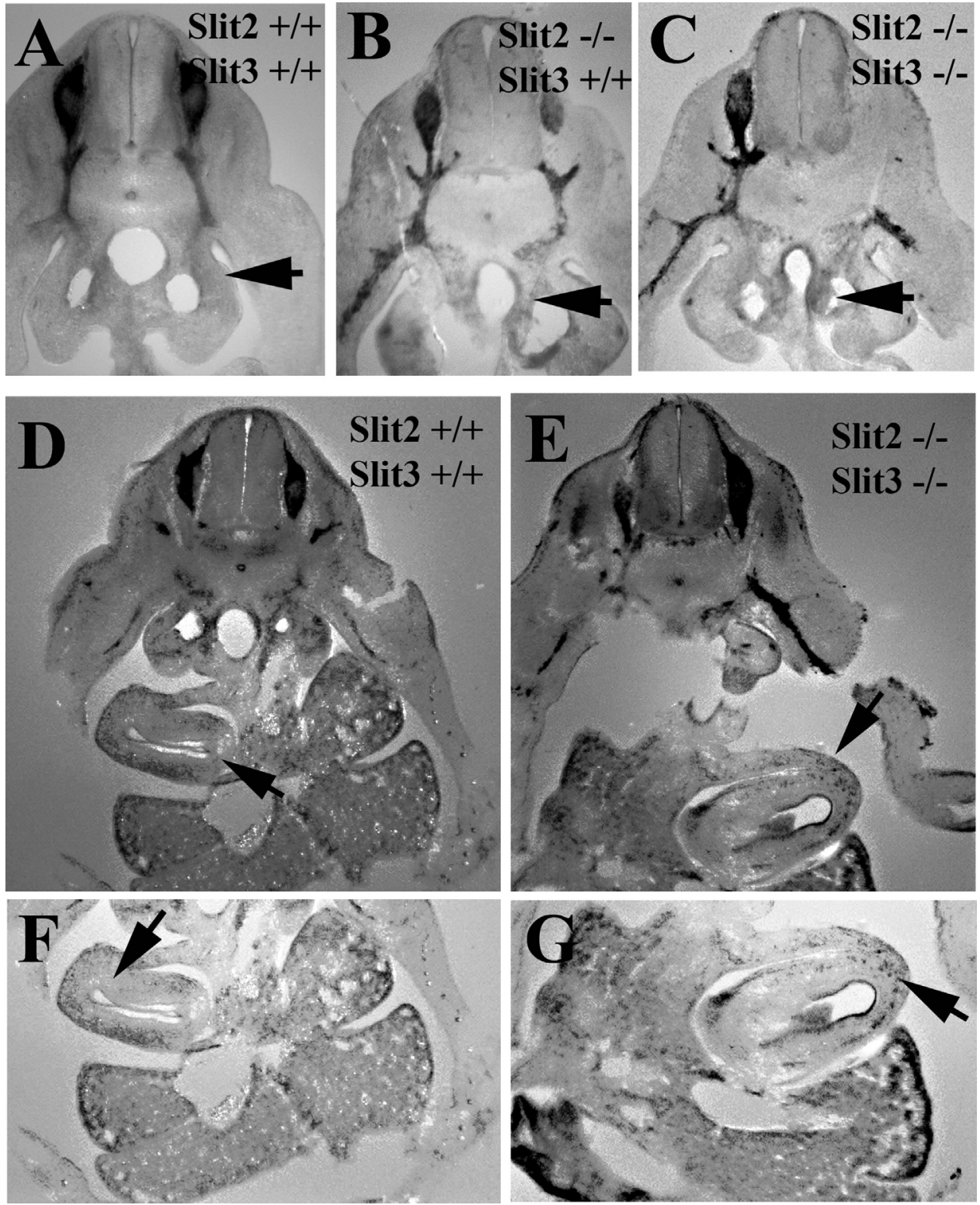

Fig. 5. Slit mutant mice have altered enteric neural crest cell migration

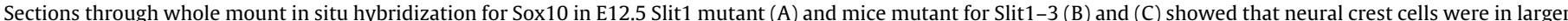

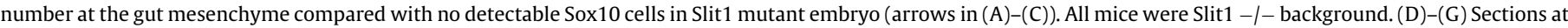

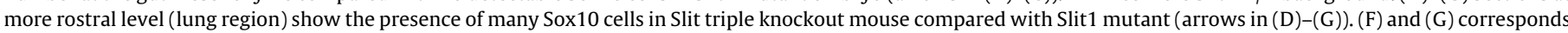

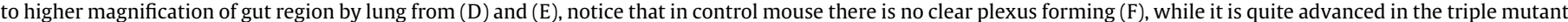
(G).

ENS development in Robo1/2 or Slit1-3 knockout mice during early stages of ENS formation. Our results showing the presence of trunk neural crest cells in the developing gut after silencing Robo2 in chicken embryos confirms that Slit molecules are responsible for keeping trunk cells away from the gut.

\subsection{Trunk neural crest cells}

Because the complexity of the neural crest itself as a stem cell population and because its inherent differences along its rostro to caudal origin, we electroporated at three different stages and locations (McKinney et al., 2013). The first thing we observed was that trunk neural crest cells rarely entered the gut, less than $50 \%$ of embryos showed RD2 cells in regions expressing Slit molecules. This was in stark contrast to what we observed when we silenced Robo2 in the caudal sympathoadrenals and sacral trunk crest: they entered Slit expressing region and the gut in larger numbers and migrated rostrally along the developing gut. Thus, silencing Robo in migrating trunk crest cells from somites 18 to 24 (sympathoadrenal) allowed these cells to enter the developing gut. This kind of observation leads to say that Slit molecules are responsible for keeping the sympathoadrenal trunk cells (ss 18-24) from entering the gut.

One puzzling observation from our Robo LOF experiments was contrary to what we were expecting to observe: the developing gut being colonized by large number of trunk RD2 GFP-positive cells in most of our experimental embryos. Regardless of the stage at electroporation, we always observed small numbers of RD2-GFP trunk crest cells from somites 8 to 17 within gut mesenchyme region. This could be due to two possible reasons working in conjunction. One stemming from the fact that, as shown by Newgreen and coworkers, trunk cells fail to match vagal crest cells in proliferation 
once in the intestinal tissue (Newgreen et al., 1980; Zhang et al., 2010). It is known that most of the enteric neural crest cells are generated later in development from few vagal neural crest pioneers migration as a rostro-caudal wave in the developing gut (Barlow et al., 2008; Burns and Le Douarin, 2001; Serbedzija et al., 1991). We now know that one reason for this differential proliferation in the gut is because sacral neural crest cells have low levels of Ret receptor compared with vagal crest (Delalande et al., 2008). Thus, the few trunk RD2 cells that entered the gut likely failed to proliferate and never increased in numbers. The second one could be due to combination of guidance cues yet unknown that prevent/guide trunk crest cells at the end of their ventromedial migratory pathways. This is very likely given the known redundancy of repulsive molecules along the migratory pathways of trunk neural crest cells (Kulesa and Gammill, 2010).

Altogether, this leads us to propose that there must be other guiding molecules to get trunk neural crest cells pass the mesentery region. This could well be another repellant present in the mesentery in conjunction with Slits, which combined with lack of strong chemoattraction to the gut itself prevented cells expressing RD2 from populating the gut in significant numbers. This is not unlikely given that neural crest cells are very plastic and variant along their rostro-caudal axis (Le Douarin et al., 2004).

The second interesting observation from this research was that sympathoadrenals trunk cells expressing RD2 were present in larger numbers than its more rostral counterparts in Slit expressing regions ventral to the dorsal aorta and even gut mesenchyme. These suggest that silencing Slit/Robo signaling in them was sufficient to allow them to enter and colonize the gut. Le Douarin's seminal trunk to vagal transplant study was indeed done with "adrenomedullary" trunk cells (ss 18-24), they did not transplant more rostral neural tubes (Le Douarin and Teillet, 1974a). Our findings that at $\mathrm{HH} 10-12$ there is no expression of Slit1/2 in the developing pharynx explains why these trunk cells (which express Robo) could enter the gut when transplanted to vagal region that lacks Slit inhibitory expression. We would like to propose here that Slit molecules are mostly responsible for keeping adrenomedullary (ss 18-24) crest away from entering the gut in a different manner to which more rostral trunk neural crest cells are (see Graphical abstract).

Our observations of the neural crest phenotype in Slit or Robo knockout mice gave support a role for Slit/Robo interaction in their development. We observed: (a) larger sympathetic ganglia by E10.5 in Slit mutants, (b) more differentiated neurons in the Robo mutant gut and (c) larger proportion of neural crest cells in the differentiating gut in the Slit mutant mice (Druckenbrod and Epstein, 2007). However, as in the instance of using RD2, we did not observe much larger numbers of Sox 10 or TuJ1 in the developing gut of the mutant mice. Despite these initial neural crest abnormalities in Robo 1/2 knockout mice, as development progresses they likely adjust cell numbers since these double knockout mice are born without hypergangliosis in either DRGs or ENS (Geisen et al., 2008; Long et al., 2004). Thus, it is assumed, as has proven for many other mutant knockout lines, that there is either compensation of Slit/Robo functions (Sabatier et al., 2004) and likely increased cell death from lack of required neurotrophic factors (NGF. GDNF, etc.) (Levi-Montalcini, 1987; Rich et al., 1987). The case for triple Slit knockout mice is different; mutant embryos do not grow to E13, making these triple knockout a lethal phenotype (Long et al., 2004).

\subsection{Sacral neural crest}

Past work from Bronner's lab showed that embryos injected with DiI at HH17, as in these experiments, showed labeled cells only in the more caudal levels of the gut, with cells within the gut mesenchyme and epithelium (Serbedzija et al., 1991). From

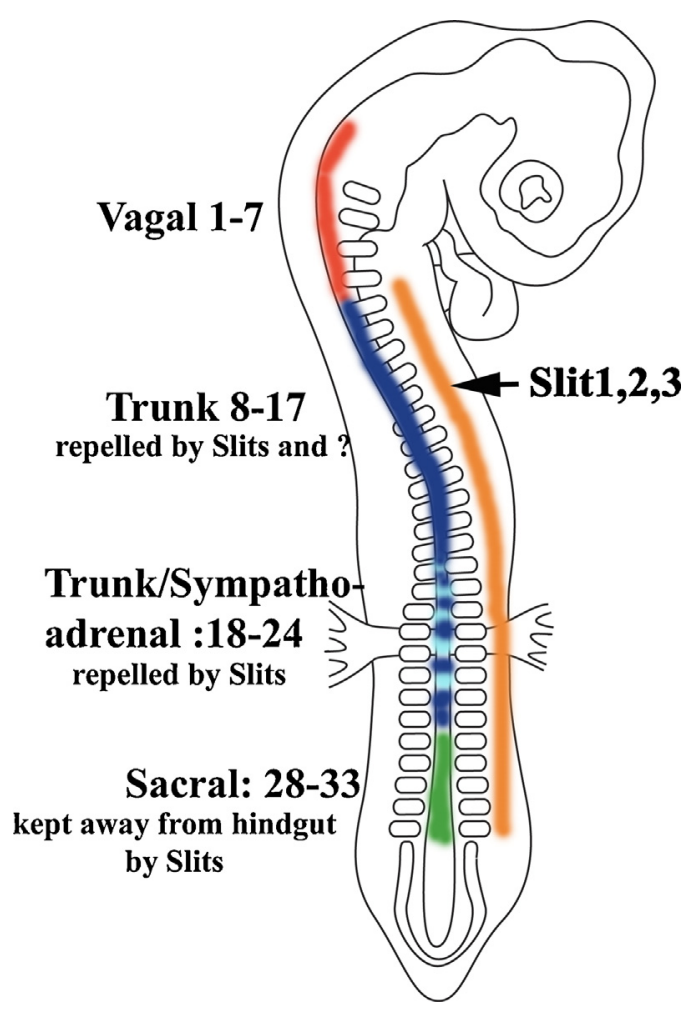

Fig. 6. This cartoon summarizes what we know about Slit/Robo interaction in neural crest migration into the gut: at vagal levels neural crest cells enter the gut by migrating through area without Slit expression. Trunk neural crest cells before somite 18 are repelled by Slits as well as another yet unknown factor(s). The trunk neural crest between somite 17 and 24 (sympathoadrenal) is kept away from the gut by Slit molecules as well as sacral crest is prevented from populating the gut before vagal crest arrives by Slit expression along the gut mesenchyme.

the early 1970s Le Douarin and co-workers elegantly showed that sacral neural crest cells migrate in a caudal-to-rostral direction during days E4-6 and will only begin to enter the gut at E7 (Burns et al., 2000; Burns and Le Douarin, 2001; Le Douarin and Teillet, 1973; Rothman et al., 1993). Our RD2 GFP cells from HH17 to HH18 electroporations were present at same anatomical locations found in quail-chick chimeras, virus or Dil experiments: developing gut epithelium (Serbedzija et al., 1991) and gut mesenchyme (Burns et al., 2000; Burns and Douarin, 1998; Burns and Le Douarin, 2001; Pomeranz et al., 1991). However, the key point is that we found these RD2 cells in large numbers $24 \mathrm{~h}$ sooner than what is expected from their stage of development. Our findings of large number of sacral crest at the hindlimb level by E4 supports a role for Slit repellants in delaying sacral crest from invading rostral gut mesenchyme ahead of vagal neural crest caudal migration (Allan and Newgreen, 1980; Barlow et al., 2008).

Furthermore, classic transplants studies carried out by Erickson and Goins found that sacral crest grafted to sympathoadrenal level would not pass beyond beneath the dorsal aorta, that is, they are repelled from entering the gut (Erickson and Goins, 2000a) as trunk crest cells are. Here we show that RD2 electroporated sacral neural crest invaded gut mesenchyme and epithelium but in much larger numbers than what was observed in those transplants with labeled cells. This finding suggests that sacral neural crest cells are also kept from migrating rostrally by Slit molecules expression in the gut mesenchyme Fig. 6.

\section{Conclusions}

The results show for the first time that: (1) Adrenomedullary trunk neural crest cells (ss 18-24) can enter the gut if Slits Robo 
receptors are silenced. (2) More rostral trunk neural crest cells (ss 9-17) are kept away from entering the gut likely by other factors (either another yet unknown repellent and/or lack of sufficient attraction). (3) Sacral neural crest cells are kept away from populating the colon region by Slit molecules. (4) Enteric neural crest cells express Robo receptors once they start forming their plexus. Thus these results give account for the differential ability of vagal but not trunk neural crest cells to invade and innervate the gut. In summary, we can conclude that Slit molecules are responsible for keeping migrating trunk neural crest cells away from the gut and sacral from entering rostral portions of the gut before vagal enteric crest reach the hind gut.

\section{Acknowledgments}

We thank Ed Laufer (Columbia University Department of Pathology and Cell Biology, New York, USA) for Slits and Robo probes and Sarah Guthrie (King's College London, Department of Neuroscience, London, England) for RoboDelta2 plasmid. We thank Vivian Lee for help with in situ hybridization. This work was supported by an NIH/NINDS AREA grant 1R15-NS060099-02 to MEdB.

\section{References}

Allan, I.J., Newgreen, D.F., 1980. The origin and differentiation of enteric neurons of the intestine of the fowl embryo. Am. J. Anat. 157, 137-154.

Barlow, A.J., Wallace, A.S., Thapar, N., Burns, A.J., 2008. Critical numbers of neural crest cells are required in the pathways from the neural tube to the foregut to ensure complete enteric nervous system formation. Development 135 , 1681-1691.

Bronner-Fraser, M., Stern, C.D., Fraser, S., 1991. Analysis of neural crest cell lineage and migration. J. Cran. Genet. Dev. Biol. 11, 214-222.

Brose, K., Bland, K.S., Wang, K.H., Arnott, D., Henzel, W., Goodman, C.S. Tessier-Lavigne, M., Kidd, T., 1999. Slit proteins bind Robo receptors and have an evolutionarily conserved role in repulsive axon guidance. Cell 96, 795-806.

Burns, A.J., 2005. Migration of neural crest-derived enteric nervous system precursor cells to and within the gastrointestinal tract. Int. J. Dev. Biol. 49, $143-150$.

Burns, A.J., Champeval, D., Le Douarin, N.M., 2000. Sacral neural crest cells colonise aganglionic hindgut in vivo but fail to compensate for lack of enteric ganglia. Dev. Biol. 219, 30-43.

Burns, A.J., Delalande, J.M., Le Douarin, N.M., 2002. In ovo transplantation of enteric nervous system precursors from vagal to sacral neural crest results in extensive hindgut colonisation. Development 129, 2785-2796.

Burns, A.J., Douarin, N.M., 1998. The sacral neural crest contributes neurons and glia to the post- umbilical gut: spatiotemporal analysis of the development of the enteric nervous system. Development 125, 4335-4347.

Burns, A.J., Le Douarin, N.M., 2001. Enteric nervous system development: analysis of the selective developmental potentialities of vagal and sacral neural crest cells using quail-chick chimeras. Anat. Rec. 262, 16-28.

De Bellard, M.E., Rao, Y., Bronner-Fraser, M., 2003. Dual function of Slit2 in repulsion and enhanced migration of trunk, but not vagal, neural crest cells. J. Cell Biol. 162, 269-279.

Delalande, J.M., Barlow, A.J., Thomas, A.J., Wallace, A.S., Thapar, N., Erickson, C.A Burns, A.J., 2008. The receptor tyrosine kinase RET regulates hindgut colonization by sacral neural crest cells. Dev. Biol. 313, 279-292.

Druckenbrod, N.R., Epstein, M.L., 2007. Behavior of enteric neural crest-derived cells varies with respect to the migratory wavefront. Dev. Dyn. 236, 84-92.

Eickholt, B.J., Mackenzie, S.L., Graham, A., Walsh, F.S., Doherty, P., 1999. Evidence for collapsin-1 functioning in the control of neural crest migration in both trunk and hindbrain regions. Development 126, 2181-2189.

Erickson, C.A., Goins, T.L., 2000a. Sacral neural crest cell migration to the gut is dependent upon the migratory environment and not cell-autonomous migratory properties. Dev. Biol. 219, 79-97.

Erickson, C.A., Goins, T.L., 2000b. Sacral neural crest cell migration to the gut is dependent upon the migratory environment and not cell-autonomous migratory properties. Dev. Biol. 219, 79-97.

Gammill, L.S., Gonzalez, C., Gu, C., Bronner-Fraser, M., 2006. Guidance of trunk neural crest migration requires neuropilin 2/semaphorin 3F signaling. Development 133, 99-106.

Gammill, L.S., Roffers-Agarwal, J., 2010. Division of labor during trunk neural crest development. Dev. Biol. 344, 555-565.

Geisen, M.J., Di Meglio, T., Pasqualetti, M., Ducret, S., Brunet, J.F., Chedotal, A., Rijli, F.M., 2008. Hox paralog group 2 genes control the migration of mouse pontine neurons through slit-robo signaling. PLoS Biol. 6, e142.

Giovannone, D., Reyes, M., Reyes, R., Correa, L., Martinez, D., Ra, H., Gomez, G., Kaiser, J., Ma, L., Stein, M.P., de Bellard, M.E., 2012. Slits affect the timely migration of neural crest cells via Robo receptor. Dev. Dyn. 241, 1274-1288.
Grieshammer, U., Le, M., Plump, A.S., Wang, F., Tessier-Lavigne, M., Martin, G.R. 2004. SLIT2-mediated ROBO2 signaling restricts kidney induction to a single site. Dev. Cell 6, 709-717.

Hamburger, V., Hamilton, H.L., 1951. A series of normal stages in the development of the chicken embryo. J. Morphol. 88, 49-52.

Hammond, R., Vivancos, V., Naeem, A., Chilton, J., Mambetisaeva, E., Andrews, W. Sundaresan, V., Guthrie, S., 2005. Slit-mediated repulsion is a key regulator of motor axon pathfinding in the hindbrain. Development 132, 4483-4495.

Jia, L., Cheng, L., Raper, J., 2005. Slit/Robo signaling is necessary to confine early neural crest cells to the ventral migratory pathway in the trunk. Dev. Biol. 282, 411-421.

Kidd, T., Bland, K.S., Goodman, C.S., 1999. Slit is the midline repellent for the robo receptor in Drosophila. Cell 96, 785-794.

Kinrade, E.F., Brates, T., Tear, G., Hidalgo, A., 2001. Roundabout signalling, cell contact and trophic support confine longitudinal glia and axons in the Drosophila CNS. Development 128, 207-216.

Krull, C.E., Lansford, R., Gale, N.W., Collazo, A., Marcelle, C., Yancopoulos, G.D., Fraser, S.E., Bronner-Fraser, M., 1997. Interactions of Eph-related receptors and ligands confer rostrocaudal pattern to trunk neural crest migration. Curr. Biol. 7, 571-580

Kulesa, P.M., Gammill, L.S., 2010. Neural crest migration: patterns, phases and signals. Dev. Biol. 344, 566-568.

Kuo, B.R., Erickson, C.A., 2010. Regional differences in neural crest morphogenesis. Cell Adhes. Migr. 4, 567-585.

Kuo, B.R., Erickson, C.A., 2011. Vagal neural crest cell migratory behavior: a transition between the cranial and trunk crest. Dev. Dyn. 240, 2084-2100.

Le Douarin, N.M., Creuzet, S., Couly, G., Dupin, E., 2004. Neural crest cell plasticity and its limits. Development 131, 4637-4650

Le Douarin, N.M., Dupin, E., Baroffio, A., Dulac, C., 1992. New insights into the development of neural crest derivatives. Int. Rev. Cytol. 138, 269-314.

Le Douarin, N.M., Teillet, M.-A.M., 1974a. Experimental analysis of the migration and differentiation of neuroblasts of the autonomic nervous system and of neurectodermal mesenchymal derivatives, using a biological cell marking technique. Dev. Biol. 41, 162-184.

Le Douarin, N.M., Teillet, M.A., 1973. The migration of neural crest cells to the wall of the digestive tract in avian embryo. J. Embryol. Exp. Morphol. 30, 31-48.

Le Douarin, N.M., Teillet, M.A., 1974b. Experimental analysis of the migration and differentiation of neuroblasts of the autonomic nervous system and of neuroectodermal mesenchymal derivatives, using a biological cell marking technique. Dev. Biol. 41, 162-184.

Levi-Montalcini, R., 1987. The nerve growth factor 35 years later. Science 237 1154-1162.

Long, H., Sabatier, C., Ma, L., Plump, A., Yuan, W., Ornitz, D.M., Tamada, A Murakami, F., Goodman, C.S., Tessier-Lavigne, M., 2004. Conserved roles for Slit and Robo proteins in midline commissural axon guidance. Neuron 42 , 213-223.

Ma, L., Tessier-Lavigne, M., 2007. Dual branch-promoting and branch-repelling actions of Slit/Robo signaling on peripheral and central branches of developing sensory axons. J. Neurosci. 27, 6843-6851.

McKinney, M.C., Fukatsu, K., Morrison, J., McLennan, R., Bronner, M.E., Kulesa, P.M., 2013. Evidence for dynamic rearrangements but lack of fate or position restrictions in premigratory avian trunk neural crest. Development 140 , 820-830.

Newgreen, D.F., Jahnke, I., Allan, I.J., Gibbins, I.L., 1980. Differentiation of sympathetic and enteric neurons of the fowl embryo in grafts to the chorio-allantoic membrane. Cell Tissue Res. 208, 1-19.

Plump, A.S., Erskine, L., Sabatier, C., Brose, K., Epstein, C.J., Goodman, C.S., Mason, C.A., Tessier-Lavigne, M., 2002. Slit1 and Slit2 cooperate to prevent premature midline crossing of retinal axons in the mouse visual system. Neuron 33, 219-232.

Pomeranz, H.D., Rothman, T.P., Gershon, M.D., 1991. Colonization of the post-umbilical bowel by cells derived from the sacral neural crest: direct tracing of cell migration using an intercalating probe and a replication-deficient retrovirus. Development 111, 647-655

Rich, K.M., Luszczynski, J.R., Osborne, P.A., Johnson Jr., E.M., 1987. Nerve growth factor protects adult sensory neurons from cell death and atrophy caused by nerve injury. J. Neurocytol. 16, 261-268.

Rothman, T.P., Le Douarin, N.M., Fontaine-Perus, J.C., Gershon, M.D., 1993. Colonization of the bowel by neural crest-derived cells re-migrating from foregut backtransplanted to vagal or sacral regions of host embryos. Dev. Dyn. 196, 217-233.

Sabatier, C., Plump, A.S., Le, M., Brose, K., Tamada, A., Murakami, F., Lee, E.Y., Tessier-Lavigne, M., 2004. The divergent Robo family protein rig-1/Robo3 is a negative regulator of slit responsiveness required for midline crossing by commissural axons. Cell 117, 157-169.

Serbedzija, G.N., Burgan, S., Fraser, S.E., Bronner-Fraser, M., 1991. Vital dye labelling demonstrates a sacral neural crest contribution to the enteric nervous system of chick and mouse embryos. Development 111, 857-866.

Shiau, C.E., Lwigale, P.Y., Das, R.M., Wilson, S.A., Bronner-Fraser, M., 2008. Robo2-Slit1 dependent cell-cell interactions mediate assembly of the trigeminal ganglion. Nat. Neurosci. 11, 269-276.

Theveneau, E., Mayor, R., 2012. Neural crest migration: interplay between chemorepellents, chemoattractants, contact inhibition, epithelial-mesenchymal transition, and collective cell migration. Wiley Interdiscip. Rev. Dev. Biol. 1, 435-445. 
Yuan, X.B., Jin, M., Xu, X., Song, Y.Q., Wu, C.P., Poo, M.M., Duan, S., 2003. Signalling and crosstalk of Rho GTPases in mediating axon guidance. Nat. Cell Biol. 5 38-45.

Zhang, D., Brinas, I.M., Binder, B.J., Landman, K.A., Newgreen, D.F., 2010. Neural crest regionalisation for enteric nervous system formation: implications for Hirschsprung's disease and stem cell therapy. Dev. Biol. 339, 280-294.
Zhu, Y., Li, H., Zhou, L., Wu, J.Y., Rao, Y., 1999. Cellular and molecular guidance of GABAergic neuronal migration from an extracortical origin to the neocortex. Neuron 23, 473-485. 